\title{
Tribus de consumo. Hacia la autosegmentación del consumidor ${ }^{1}$
}

Recibido: 11 de agosto de 2015

Aceptado: 10 de febrero de 2016

Publicado: 30 de noviembre de 2016

\author{
Nicolás Martín Ortiz Esaine \\ nortiz@pucp.pe \\ Pontificia Universidad Católica del Perú
}

Resumen: El siguiente artículo busca comprender el consumo desde una mirada de las tribus de consumo. A su vez, busca posicionarse como una nueva alternativa metodológica para las empresas de estudios de mercados, como un criterio innovador de segmentación. Se exponen las exploraciones de visitas de campo a diversas tribus de consumo de Lima Metropolitana. En total nos sumergimos en nueve comunidades culturales: skaters, gamers, surfers, k-popers, atléticos, hipsters, otakus, melómanos y graffiteros. Nos enfocamos primero, en la relación sociedad y tribu; segundo, sus características y aplicaciones de marketing. El artículo concluye con una reflexión acerca de elementos claves del criterio de segmentación por tribus de consumo.

Palabras clave: Investigación de mercados, tribus de consumo, segmentación, etnografía.

Abstract: The following article seeks to understand the consumer from a viewpoint of the tribes of consumption. In turn, position itself as a new alternative methodology for market research companies as an innovative approach to segmentation. Field explorations visits are exposed to various tribes' consumption of Lima. In total we dive in nine cultural communities: skaters, gamers, surfers, k-popers, athletics, hipsters, otaku, music lovers and graffiti artists. We focus first on society and kindred relationship. In second hand, its features and applications of marketing. The article concludes with a reflection on key elements of the criterion of consumer segmentation tribes.

Key words: Market Research, Consumer Tribes, Segmentation, Ethnography.

1 El presente estudio ha sido posible gracias a la supervisión de campo del estudiante de Sociología Wins Kevyn Dueñas y los alumnos de Publicidad de la Pontificia Universidad Católica del Perú e ISIL. 


\section{Introducción}

Las empresas comienzan a entender que por encima de sus propias necesidades están las de los consumidores. De esta forma, resulta necesario que el mercado sepa satisfacer no solo las necesidades básicas, sino también las simbólicas de los nuevos consumidores limeños. Para ello, se debe contar con las herramientas pertinentes para alcanzarlo.

En los últimos veinte años, las empresas en el Perú han ido adquiriendo una actitud más profesionalizada en los diferentes procesos de la gestión empresarial. Los estudios de mercado no son ajenos a esta tendencia. La renovación conceptual y metodológica se ha ido renovando principalmente por las diversas consultoras. El caso de Consumidores \& Mercados (hoy Arellano Marketing) ya en 1996 planteaba las limitaciones de la tradicional segmentación socioeconómica, proponiendo una nueva forma de aproximación a los diferentes estilos de vida.

Más adelante, el incremento de la capacidad adquisitiva (promovida por el crédito bancario) permitió el ensanchamiento de las clases medias, obteniéndose así nuevas herramientas de comunicación, tales como la Internet y los canales internacionales por cable. Todo este fenómeno permitió el ingreso de nuevos códigos culturales, asimilados principalmente por estos sectores. La adquisición de estos códigos y una mayor capacidad adquisitiva generó cambios en el acto de consumo, configurándose un problema principalmente para las empresas de estudio de mercados.

En todo caso, la adquisición de estos nuevos códigos culturales generó la diversificación del gusto, concretizándose en lo que denominamos "tribus de consumo" como espacios alternativos frente al consumo de masas. Fue necesario, desde las empresas de estudios de mercados, cambiar el enfoque deductivo y comenzar a valorar los detalles más específicos del acto de consumo de estos nuevos grupos.

El concepto de tribu de consumo nos ayuda a comprender no sólo lo que consume los miembros de una comunidad de consumo, sino que sobre la base del método etnográfico (observación y entrevistas no estructuradas) podemos entender la posición que tienen estos elementos (o productos) dentro del ritual diario de la tribu. Esta forma de abordar es ventajosa principalmente para encontrar nuevos mercados y tener una comunicación publicitaria pertinente en los consumidores.

\section{Objetivos}

La presente investigación tuvo como objetivo general perfilar segmentos de consumidores desde la perspectiva de nichos culturales, que permitan revelar criterios de identidad firmes que vinculen al consumo. Se tienen como objetivos específicos:

- Definir el perfil de los integrantes de segmento, de diferentes nichos de consumidores, agrupados bajo la identificación con un consumo cultural. 
- Describir las actitudes del colectivo en torno a la actividad cultural definida y los mecanismos de identificación que producen.

- Determinar las prácticas que inciden en el consumo de productos.

Con todo ello, podemos tener un panorama inicial de los aspectos que caracterizan a estos grupos de consumidores

\section{Metodología}

Los mecanismos tradicionales de segmentación (geográfica, sociodemográfica, psicográfica y conductual) agrupan a los consumidores por una característica que los asemeje. Con ello presuponen (con una lógica deductiva) una conducta de consumo predeterminada. Para esto, el sujeto cae de forma predeterminada a una categoría, sin necesidad de sentirse adscrito o formar parte de la construcción de esta identidad.

Por ello, se desarrolló un estudio de diseño etnográfico, realizando una inmersión en 9 comunidades culturales, por un lapso de 4 semanas en cada una. La misma consistió en observaciones participantes, observaciones no participantes, 4 entrevistas no estructuradas (en ambiente natural) en contexto con personajes representativos y la convivencia con estos grupos durante jornadas reiterativas. El trabajo de campo se realizó en distintas etapas, durante un mes en cada comunidad, entre los años 2014 y 2015.

\section{Hipótesis}

El estudio que emplea nichos culturales o "tribus de consumo" permite explorar mecanismos alternativos de segmentación por nichos, con un modelo inductivo más que deductivo, en el que prima la identificación del consumidor con los valores culturales del conjunto y sus co-integrantes. Asimismo, permite la detección de tendencias del consumo en formación, así como un vínculo directo del comportamiento grupal con la prospección de consumo.

\section{Códigos culturales como claves de oportunidades de negocios ${ }^{2}$}

El término "aldea" remite a una comunidad agrupada por un espacio concreto que se reconocen por una similitud física. El espacio físico, étnico y tradicional obliga a una reproducción del sistema operante tal cual ya ha sido establecido. Las tribus se reconocen por una identidad cultural en términos de pensamiento y objetos simbólicos. Sus relaciones

2 Muchos de los pasajes de este apartado se encuentran, aunque en una versión más resumida, en el blog del autor (Ortiz, 2015). 
van más allá del espacio físico: la comunidad está en búsqueda de intercambios, generando continuos contagios que van desde propagar sus creencias como asimilar nuevas fórmulas.

El auge de los medios de comunicación y la economía global, en los sesentas, llevó a McLuhan a vaticinar la re-composición de una "nueva aldea", en este caso, global. Públicos congregados alrededor de una fogata (de imágenes y sonido), asimilando ideas y formando pensamiento en bloque. Sin embargo, este proceso parece haberse sofisticado, llevando así a la atomización de tribus globales básicamente por dos grandes fenómenos en la forma del comportamiento de los públicos al consumir medios: a) multiplicación de las pantallas y b) tiempo diferido en el consumo de medios. A su vez, esto conlleva cambios en el comportamiento del consumidor, re-tribalizándose el consumo por: c) compra de experiencias y $d$ ) deslocalización de la compra ${ }^{3}$.

La formación de una tendencia de consumo no es un acto individual, sino parte de un sistema, un hecho social propio de la influencia de varios actores, agentes y un contexto determinado:

\begin{abstract}
"Ningún diseñador, empresa o agencia publicitaria es totalmente responsable de crear la cultura popular. Cada producto, ya sea un álbum exitoso, un automóvil o un nuevo estilo de ropa, requiere la participación de muchos individuos diferentes. Un sistema de producción cultural (SPC) es el conjunto de individuos y organizaciones responsables de crear y comercializar un producto cultural" (Solomon, 2008: 574).
\end{abstract}

Los códigos culturales son un concepto desarrollado por el psicoterapeuta Clotaire Rapaille. Este se refiere a los valores que agrupan a los consumidores y que predeterminan su conducta, incluyendo sus motivaciones de consumo. Este autor ha desarrollado proyectos para marcas internacionales, los cuales se caracterizaron por requerir una interpretación profunda de las percepciones subyacentes a los consumos, según un análisis comparativo de las culturas. Veneziani realiza un balance y adaptación de estos principios al mercado argentino de la moda, poniendo en operación los alcances de este método:

"Para el psiquiatra francés, cada cultura posee un esquema cultural propio que es una prolongación del esquema biológico. Es decir, el esquema

3 “Con el desarrollo del internet, los medios masivos y el consumismo, las profecías más comunes vaticinaban el aislamiento del consumidor frente a un aparato electrónico. Por el contrario, el sociólogo Marshall McLuhan, en los años sesenta, propuso el inicio de una aldea global donde los sujetos en el mundo se reconectaban a través de mensajes y medios compartidos, rompiendo barreras de espacio y tiempo. En pleno tercer milenio, en la era de las redes sociales, podemos entender que los sujetos y sociedades se retribalizan, lo que hace imposible seguir analizando al consumidor en solitario sin comprender su entorno, sociedad y cultura. Sin embargo, lo que estaríamos presenciando es que, en la era de las redes sociales, la generación de jóvenes contemporáneos rompe las barreras de espacio y tiempo, y nos enfrentaríamos a un proceso de retribalización de sujetos y colectivos en los universos virtuales, pero, a la par, esta generación se estaría desconectando de sus entornos sociales inmediatos. Ello nos estaría obligando a modificar los enfoques de investigación y comprensión de las identidades de personas y colectivos en las sociedades contemporáneas" (Ortiz, 2016: 138-139). 
biológico determinaría una necesidad y el esquema cultural lo expresaría dentro de los parámetros de una determinada cultura. Así, estas tensiones entre ambos ejes también se verifican en las distintas culturas. En cada una de ellas existen muchos pares de paradigmas que se oponen entre sí. La cultura estadounidense, por ejemplo, oscila entre distintas tensiones. Un extremo sería la libertad y su opuesto la prohibición. Inclusive, aunque los ejes no varíen, sí lo hacen las inclinaciones hacia un extremo o el otro del mismo, de acuerdo con las épocas" (Veneziani, 2014: 82).

En este artículo, el consumo es considerado como un acto racional del consumidor con propósitos comunicacionales. El consumo es el sitio donde la cultura proporciona la pelea de discursos y cambios, ya que los bienes adquiridos por el consumidor tienen un especial código determinado e impuesto por las racionalizaciones de este, que responden a lo que su entorno le determina y que continúa siendo prácticamente su cultura, sus necesidades y atributos, los cuales determinan y posicionan su cotidianidad, traducida muchas veces por la academia en las categorías sociológicas de análisis.

Sin embargo, consideramos que para comprender los códigos de los objetos no es suficiente con consumirlo, sino que es necesario tener las condiciones necesarias que nos permitan poder consumirlo y, a partir de ello, entender los códigos de estos objetos. Las condiciones se expresan en la tensión de nuestras facultades biológicas con los códigos culturales que vamos adquiriendo. Para Reynolds (2012), los objetos no poseen las propiedades y efectos en sí mismos, sino que son las operaciones de distinción que realizamos lo que configura a los objetos con los cuales interactuamos, por lo que nuestra estructura biológica es la que determina el significado de los objetos.

Esto quiere decir que la estructura biológica permite la comprensión de los códigos de la tribu el cual nos permite poder formar parte de ella. Por ejemplo, para una persona con baja habilidad kinestésica, por más próxima que se encuentre con la tribu surf, no podrá ingresar a ella, ya que necesita de esta habilidad para realizar las prácticas de esta tribu y, a partir de ello, comprender el significado de sus objetos. Empero, una persona con habilidades kinestésicas tiene la posibilidad de identificarse con la tribu surf porque puede realizar estas prácticas y encontrar el significado de los objetos en conjunto con el grupo. Esto permite entender que el significado de una tabla de surf para un miembro de la tribu es distinto para una persona que esta fuera de ella, como también la capacidad de diferenciar la calidad de una marca de una tabla de surf frente a otra marca. Por lo tanto, el valor que tienen los objetos varía en relación con la capacidad que tienen las personas de poder encontrar las cualidades de estos en conjunto con el grupo.

\section{Etnografía como método}

El método etnográfico supone un proceso de inmersión sucesiva en la comunidad, la cual se logra en un período de tiempo o la continua visita a una comunidad, a partir de conocer a sus miembros. El logro de la confianza, que se objetiva en el poder ser reconocido por 
los miembros de la comunidad (por un nombre o función) es un confirmación de inmersión exitosa. Por ello, se ha propuesto la siguiente matriz, de utilidad para el estudio del consumo, identificándose tres partes, entendidas como etapas sucesivas:

- Comunidad: lo fijo, es decir, lo que se orienta a la permanencia y estabilidad que genera un marco de referencia para la tribu. Implica que el investigador reconstruya las variables que conforman la identidad (y diferencia con otros). Con ella se logra identificar a los actores claves y las claves que generan cohesión (identidad), el espacio donde se desarrolla la comunidad y que generan un contexto incluyente (entorno); así como las normas, castigos, refuerzos y jerarquías que se respetan (poder). Esta comunidad se describe a través de mapas que detallan las formas de operación de estos elementos.

- Cotidianeidad: lo contingente, es decir, aporta las variables que generan cambio o transformación propia del devenir corriente de la vida en comunidad, lo que evoluciona. Implica que el investigador rastree los procesos que están en transformación, que podrían convertirse en tendencia. Los elementos distintivos de la intervención se analizan en este apartado (objetos o productos), los hábitos con carácter simbólico vinculados al consumo (rituales), así como las formas en las que opera el sistema que los hace sobrevivir y emerger (economía).

- Comunicación: lo dicho, es decir, lo que se expone exteriormente por la comunidad. Implica auditar los mensajes verbales y no verbales que codifican la convivencia. Los elementos distintivos de la cosmovisión que integra a los miembros y les da sentido (mitología), las formas de comunicación en su manifestación verbal (lengua) y simbólica (iconos).

Figura 1: Método etnográfico de consumo.
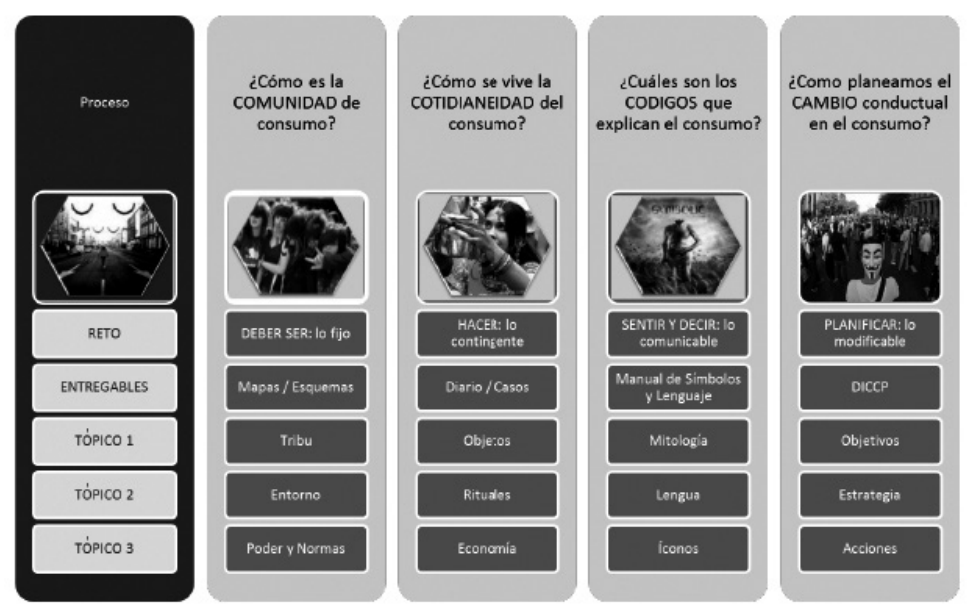

Fuente: Elaboración propia. 


\section{Resultados}

En este apartado se realiza análisis de las diferentes tribus de Lima Metropolitana (figura 2) en donde se resalta las habilidades propias de la tribu que les permiten realizar prácticas y así entender y dar nuevos significado a sus objetos, como también definir la posición en la que se encuentra.

Como se había mencionado, la estructura biológica permite formar parte de una tribu que influye en el significado que se le da a los objetos, por lo que un objeto puede tener significados distintos. Por ejemplo, no es el mismo una computadora para un escritor que para un gamer: para el primero es un espacio donde puede expresar sus ideas y para el segundo es un campo de batalla. Sin embargo, para ambos, la computadora es un elemento importante, ya que sin ella no podrían realizar sus prácticas. Esta diferenciación nos ayuda a comprender que la comunicación comercial de las computadoras debe de tener en cuenta a quien se está dirigiendo y como contextualiza las necesidades. 
Figura 2: Rasgos de las 9 comunidades culturales.

\begin{tabular}{|c|c|c|c|}
\hline TRIBU & PERFIL & CÓDIGO & MOTIVACIONES \\
\hline GAMERS & $\begin{array}{l}\text { Introvertidos ante personas ajenas a su } \\
\text { grupo. Interesados en las tramas de los } \\
\text { videojuegos y en crear vínculos amistosos } \\
\text { con personas que conozcan de estos. }\end{array}$ & $\begin{array}{l}\text { "Un gamer pierde una vida para } \\
\text { ganar miles". }\end{array}$ & $\begin{array}{l}\text { La libertad de ser lo que se } \\
\text { desee ser y lograr (a través de } \\
\text { sus metas y estrategias) lo que } \\
\text { se proponga. }\end{array}$ \\
\hline SURFERS & $\begin{array}{l}\text { Apariencia despreocupada, actitud } \\
\text { amistosa y libre. Buscadores de } \\
\text { adrenalina y de distensión a través del } \\
\text { surf. Suelen practicar otros deportes } \\
\text { como el skate. }\end{array}$ & $\begin{array}{l}\text { "Surfear lo es todo. Cuando entro } \\
\text { al mar me siento liberado y siento } \\
\text { que me conecto con los hermanos } \\
\text { que ya no están con nosotros". }\end{array}$ & $\begin{array}{l}\text { Creencia en el regreso cíclico } \\
\text { de las personas y cosas a } \\
\text { través del mar. }\end{array}$ \\
\hline SKATERS & $\begin{array}{l}\text { Apariencia relajada, aunque competitivos } \\
\text { y perseverantes. Evaden los conflictos. } \\
\text { Los une y caracteriza una posición crítica } \\
\text { contra el orden público y el sistema } \\
\text { económico. }\end{array}$ & $\begin{array}{l}\text { "Siempre tenemos problemas } \\
\text { con la autoridad; lo nuestro es } \\
\text { escapar". }\end{array}$ & $\begin{array}{l}\text { Búsqueda de un grupo } \\
\text { protector donde se establezcan } \\
\text { fuertes lazos de camaradería } \\
\text { similares a una familia. Eje de } \\
\text { unión: la música. }\end{array}$ \\
\hline K-POPERS & $\begin{array}{l}\text { Amables (pero tímidos) con personas que } \\
\text { no son de su entorno. Demuestran euforia } \\
\text { cuando se trata de sus grupos favoritos. }\end{array}$ & $\begin{array}{l}\text { "Dejar todo de mí por estar un } \\
\text { poco más cerca de ellos". }\end{array}$ & $\begin{array}{l}\text { Deseo de generar vínculos de } \\
\text { amistad y de auto-descubrirse a } \\
\text { través del k-pop. }\end{array}$ \\
\hline ATLÉTICOS & $\begin{array}{l}\text { No se ha definido una personalidad } \\
\text { dominante. Valoran los eventos deportivos } \\
\text { como una oportunidad de sentir sus } \\
\text { límites y los resultados de su constancia. }\end{array}$ & $\begin{array}{l}\text { "Hacer deporte nos hace grupo, } \\
\text { mejora nuestro estilo de vida y } \\
\text { siento que crecemos". }\end{array}$ & $\begin{array}{l}\text { Recreación y tiempo de } \\
\text { ocio orientado al desarrollo } \\
\text { personal. }\end{array}$ \\
\hline HIPSTERS & $\begin{array}{l}\text { Alegres, carismáticos y sociables. } \\
\text { Identificados con el arte, la música, el } \\
\text { teatro, la danza, entre otros. Asisten a } \\
\text { eventos como parte de su rutina. }\end{array}$ & $\begin{array}{l}\text { "Que sepan que estuvimos en el } \\
\text { evento. Siento que puedo perder } \\
\text { uno de los mejores momentos de } \\
\text { mi vida". }\end{array}$ & $\begin{array}{l}\text { Asistir a eventos culturales y } \\
\text { actualizarse constantemente } \\
\text { sobre su entorno, reforzando } \\
\text { así la imagen que desean } \\
\text { proyectar de sí mismos. }\end{array}$ \\
\hline OTAKUS & $\begin{array}{l}\text { Hombres y mujeres poseen perfiles } \\
\text { distintos. Los primeros son menos } \\
\text { expresivos y más concisos, mientras que } \\
\text { las mujeres son más efusivas, utilizando } \\
\text { mayor cantidad de accesorios vinculados } \\
\text { a los animes / mangas. }\end{array}$ & $\begin{array}{l}\text { "Más que ver un dibujito animado } \\
\text { es verte reflejado en un personaje } \\
\text { que llega a sus metas, a } \\
\text { empujarte y ser cada vez mejor". }\end{array}$ & $\begin{array}{l}\text { Lograr sus metas personales } \\
\text { y transformar el mundo a } \\
\text { través de la emulación de las } \\
\text { características de un personaje } \\
\text { determinado que resulten } \\
\text { positivas. }\end{array}$ \\
\hline MELÓMANOS & $\begin{array}{l}\text { Personas cálidas y calmadas con } \\
\text { mucho conocimiento sobre música. Se } \\
\text { encuentran entre la búsqueda de la } \\
\text { identidad propia y del disfrute del objeto. }\end{array}$ & $\begin{array}{l}\text { "Frente a un mundo efímero, } \\
\text { retornar a un espacio y tiempo } \\
\text { donde sentirse más pleno". }\end{array}$ & $\begin{array}{l}\text { Utilizan la música como un } \\
\text { modo de conectar con lo que } \\
\text { desean sentir en su intimidad, } \\
\text { también, como fuente de } \\
\text { conocimiento para interactuar } \\
\text { con los demás. }\end{array}$ \\
\hline GRAFFITEROS & $\begin{array}{l}\text { Apariencia relajada, su habla es coloquial } \\
\text { y se identifican con apodos. Poseen un } \\
\text { fuerte deseo de autoexpresión o visión de } \\
\text { vida que en ocasiones desafía la ley y las } \\
\text { críticas de los ajenos a este arte. }\end{array}$ & $\begin{array}{l}\text { "Los equivocados son el resto. } \\
\text { Expresarse y ser auténtico es lo } \\
\text { normal". }\end{array}$ & $\begin{array}{l}\text { Búsqueda de la armonía en } \\
\text { colores y formas. También } \\
\text { un deseo de cambiar el statu } \\
\text { quo, desafiando a los que no } \\
\text { comprenden esta actividad. }\end{array}$ \\
\hline
\end{tabular}

Fuente: Elaboración propia. 


\subsection{Gamers}

a) Comunidad: el principal lugar de esta tribu se encuentra en el Centro Comercial Arenales o en áreas cercanas a ciertas universidades, donde se realizan concursos internacionales.

b) Cotidianeidad: los gamers expresan una personalidad introvertida ante personas que no son de su grupo. Sin embargo, se consideran personas sociables que comparten su tiempo con distintos grupos. Los criterios que utilizan para escoger sus amistades son aquellos individuos que están a la vanguardia en este tema, tales como desarrolladores de videojuegos, personas que estén armando una activación o que promueven la cultura gamer.

c) Comunicación: los gamers se interesan por las historias de los videojuegos. Para ellos, la trama debe ser consistente y atractiva, que sus acciones y estrategias les permitan incidir en la trama del juego. Consumen películas o comics relacionado a videojuegos y aparatos clásicos del pasado (consolas vintage).

d) Aplicación del marketing: la computadora es el principal elemento, es el punto de partida para sumergirse y formar parte de esta tribu. Hasta ahora no hay tiendas de computadoras exclusivas para gamers, con dispositivos que optimicen la experiencia en el juego. Los gamers han sido cuestionados por el tiempo que le dedican a estas actividades. Su nutrición es cuestionada, por lo que requerirían una alimentación acorde con sus hábitos y rutinas diarias.

\subsection{Surfers}

a) Comunidad: se encuentran en las principales playas del sur de Lima. Suelen aprovechar la estación de verano para sus entrenamientos e inducción de nuevos integrantes. La estación de invierno es exclusiva para la competencia y maniobras de mayor complejidad.

b) Cotidianeidad: los surfers tienen una apariencia despreocupada, son personas amistosas, libres, que tienen un mismo gusto por las olas. El bronceado de su piel y el quemado de su pelo son características propias de los surfers. La principal motivación de los integrantes de esta comunidad es la adrenalina que les genera su actividad, luego el perfeccionamiento constante del día a día.

c) Comunicación: sus intereses están en otros deportes extremos, tales como el skateboarding y el motocross. La música también figura en sus preferencias.

d) Aplicación del marketing: el elemento principal es la tabla de surf. Para aumentar la seguridad en este deporte, se han añadido accesorios de protección como el wetsuit. Otro elemento se encuentra en la música: la radioemisora Doble Nueve (99.1 FM) ha sabido conectar la música extranjera con la cotidianidad de esta tribu. El arte culinario también ha sabido adaptarse: la decoración de sus platos simbolizan los elementos de esta comunidad, que pueden apreciarse en los restaurantes de las playas del sur de Lima. 


\subsection{Skaters}

a) Comunidad: los encontramos en los diversos skateparks de Lima o calles con muros altos.

b) Cotidianeidad: los skaters son relajados, competitivos y perseverantes. Se divierten entre ellos. Evitan los problemas y los conflictos. Algunos tienen un habla coloquial y callejero. La relación entre ellos es de compañerismo y apoyo mutuo. Consideran que todos son iguales y que no existen, entre ellos, clases sociales. Los identifica el manejo de la tabla. Hablan de técnicas sobre la base de sus propios términos.

c) Comunicación: su principal interés es la música, especialmente aquella que motiva su actividad. El rap es un género muy escuchado por ellos (Snoop Dog, Wiz Khalifa, Dr. Dre, Rapper School, entre otros).

d) Aplicación del marketing: la industria para este deporte está desarrollada: varias marcas satisfacen estas necesidades. Es por ello que las tiendas de ropa y accesorios especializados son espacios para adquirir prendas holgadas (estas les permiten realizar maniobras). Las zapatillas, por excelencia, son de corte ancho y acolchonado. La música les brinda motivación suficiente para realizar estas actividades, pero no cuentan con una emisora exclusiva que los identifique.

\subsection{K-popers}

a) Comunidad: el Parque Castilla es el lugar más concurrido por los k-popers. Es un lugar seguro, amplio y de espacios grandes, donde se pueden practicar coreografías. Un lugar fijo de ensayo y reunión.

b) Cotidianeidad: son personas amables con los demás, pero tímidos con personas que no son de su entorno. Suelen mostrar sus emociones con gente de su entorno, muestran euforia cuando hablan de sus gustos musicales o ídolos. Cuando alguien dice una palabra que le recuerda alguna canción k-pop, terminan cantando y bailando en público. Son generalmente grupos de varios chicos o chicas. Así, estas personas suelen escoger a un cantante o elenco determinado y comparten su gusto con otros grupos afines. Se enteran de sus eventos por Facebook y entran a Twitter sólo cuando hay conciertos en Perú y exista un tweet-tendencia.

c) Comunicación: están interesados en accesorios personalizados de sus artistas favoritos, así como música y hasta comida representativa de ese país. Realizan pedidos (generalmente discos) que podrían demorar hasta dos meses.

d) Aplicación del marketing: tienen la necesidad de consumir videos o fotos que les permitan imitar la vestimenta y coreografía de sus cantantes favoritos. Esto se complementa con el consumo de llaveros personalizados, los cuales generan una sensación de aproximación hacia sus artistas. Dicha tribu necesita de nuevos espacios donde pueda complementarse con otros elementos, ya sean servicios de estéticas 
o tiendas de ropa. Pueden surgir otras alternativas a Arenales como el único lugar exclusivo de consumo.

\subsection{Atléticos}

a) Comunidad: el concepto "atlético" incluye una variedad de deportes. Por esta razón que podemos encontrarlos en diversos espacios. Claro ejemplo es el Parque de la Felicidad, en los alrededores del Pentagonito (San Borja), donde confluye una gran masa de atléticos de diferentes disciplinas.

b) Cotidianeidad: no se ha definido una personalidad dominante en esta tribu. Encontramos personas extrovertidas e introvertidas. Pero hay algo en común en los atléticos que los motiva a seguir con esta actividad que es el control del bienestar de sus propios cuerpos y las consecuencias que trae: desarrollo personal, disciplina, liberación de tensiones y la capacidad de poder socializar.

c) Comunicación: interesados en elementos que ayuden a alcanzar sus objetivos, tales como una buena dieta (que brinde los niveles calóricos adecuados) y ropa (que les permita practicar su disciplina con comodidad).

d) Aplicación del marketing: son requeridas las prendas ajustadas y cómodas para sus ejercicios diarios. Existe una variedad de marcas en prendas especializadas por disciplinas. Empero, no hay una especialización en la alimentación por disciplina: los alimentos para deportistas aún son muy generales.

\subsection{Hipsters}

a) Comunidad: son personas de diferentes distritos de la capital. Los podemos encontrar principalmente en los teatros o bares de Barranco.

b) Cotidianeidad: son personas alegres, carismáticas y sociables. Se identifican principalmente con el arte, la música, el teatro, la danza, las artes escénicas, entre otras manifestaciones. El ritual se desencadena en todo momento: desde la búsqueda constante de nuevos eventos (por las redes sociales) hasta los encuentros con amigos para ir a los bares y al teatro.

c) Comunicación: ahorran para asistir a todos los eventos que puedan. La compra directa es importante. El ticket connota la confianza de haber conseguido la entrada para el evento y el número de asiento garantiza la calidad del momento.

d) Aplicación del marketing: el principal elemento es el evento, ya sea de teatro, danza o música. Sin embargo, el elemento próximo es el ticket que garantiza la entrada. Hasta ahora no encontramos aplicativos de fácil búsqueda que recopilen los próximos eventos, con información de precios y ubicación de puntos de venta para la compra directa de las entradas. 


\subsection{Otakus}

a) Comunidad: el lugar por excelencia es el Centro Comercial Arenales, otrora quebrado espacio comercial, ora revitalizado por esta comunidad, empleando los cines cerrados para la realización de "maratones" de visionado. En ese espacio se encuentra los elementos que complementan sus prácticas cotidianas.

b) Cotidianeidad: se compenetran con el personaje como impulso para lograr sus metas y ser cada día mejor. Sin embargo, al adoptar el personaje, desenvuelven roles distintos, según su género. Ambos géneros mantienen seguridad al hablar, pero la precisión de las respuestas se ve más en los hombres y la efusividad al hablar en las mujeres (estas imitan el tono de voz de sus personajes). El elemento de identificación es el anime: a partir de este se forman diversos grupos que representan a un anime específico. Toma el liderazgo quien conoce más sobre el tema, puesto que guía las interacciones del grupo.

c) Comunicación: el interés del miembro se mimetiza con los intereses del personaje. Por esta razón, el interés se enfoca principalmente en la indumentaria y en las combinaciones de las prendas, con el propósito de parecerse más a ellos.

d) Aplicación del marketing: el principal elemento es el canon de animes que los introduce al personaje. La imitación a estos personajes lleva consigo el consumo de fotos y videos que les permiten entender la trama del anime, los comportamientos de los personajes y sus gestos para luego ser imitados. Al igual que los k-popers, necesitan de otros espacios que satisfagan su demanda, tales como servicio de estéticas o de indumentarias.

\subsection{Melómanos}

a) Comunidad: podemos encontrarlos en ferias o tiendas exclusivas de discos de vinilo.

b) Cotidianeidad: son personas muy cálidas y calmadas, con mucho conocimiento sobre la música antigua. El elemento de identificación (más allá que el disco de vinilo) es lo que simboliza: es la historia enrolada en ella y lo exclusivo que es obtenerlo. Se identifican por la calidad del sonido, por los momentos que revive al reproducirlo.

c) Comunicación: tienen un interés fuerte por la música, lo que los lleva a buscar no sólo el disco de vinilo, sino también discos compactos originales de colección. Entre ellos hay una variedad de gustos: algunos son más puristas, otros más flexibles y otros más visionarios.

d) Aplicación del marketing: el renacer del uso, la compra de discos, el desarrollo de reproductores, el surgimiento del mercado de reparaciones, espacios de consumo y eventos de experiencia que ha generado esta comunidad son incrementales. Más que una tendencia, son parte de la industria sonográfica. 


\subsection{Graffiteros}

a) Comunidad: los podemos encontrar en diferentes lugares de Lima, principalmente en espacios de paredes amplias o en lugares no muy concurridos, especialmente en las madrugadas.

b) Cotidianeidad: son personas de habla coloquial y se identifican con apodos o sobrenombres. El elemento de identificación es la expresión del mensaje mediante el dibujo con sprays. La adrenalina (al sentirse acechados por la autoridad) es el fin en sí mismo, es símbolo de protesta. Para otros, sólo es por placer de realizarlos.

c) Comunicación: interesados en la combinación de colores y una buena elección de sprays. Buscan grupos musicales acordes con la fluidez de sus dibujos.

d) Aplicación del marketing: el principal elemento de esta actividad son las paredes de las calles donde pueden expresar sus ideas o emociones. El spray es un elemento importante que permite ejecutar esta actividad. En Lima no existen emisoras exclusivas para estas tribus.

\section{Conclusiones}

La "oferta" (que agrupa a todos los productores y marcas) ha actuado en el mercado local de forma unilateral, buscando imponer sus productos, lógicas de producción y códigos de comunicación. Esto surge al considerar a los consumidores como bloques de comportamiento predeterminado, sin esforzarse en levantar información directa de campo. Ante ello, la demanda ha sabido desentenderse de la invasión publicitaria y la guerra comercial, conformando tribus de consumo y, con ello, mantener vivos los mecanismos de reproducción cultural.

La conformación de tribus de consumo requiere de tres elementos que les otorga identidad y forman su "pegamento" social.

a) Entorno: La relación de las tribus con su entorno varía con relación a su grado de diferenciación percibido. Algunas tribus tienen una relación de conflicto y otras pueden pasar desapercibidas. Esto pone a algunas tribus en la defensiva y otras en la búsqueda de su expansión.

"Quiero que esta generación sepa lo que significan los vinilos para nuestra comunidad, educarlos" (melómano).

Los melómanos (personas que se enfocan en valorar la música antigua) no entran en conflicto porque no tienen un espacio físico que sea arrebatado o un elemento que salte a la vista y los diferencien. Lo mismo sucede con los gamers, los culties y los atléticos, donde su identificación se basa más en prácticas que aparentemente se asemejan a la cultura de 
masas. Sin embargo, un skater es más fácil identificarlo por los elementos que lo rodean. Para algunos, su presencia es una amenaza o mala influencia, por lo que son retirados de los lugares que frecuentan. La actitud de esta tribu es más a la defensiva, con el propósito de mantener sus prácticas.

"Para los serenazgos, sus peores enemigos son los skaters" (skater).

b) Performance: la competencia técnica, o el tener las habilidades adecuadas, no sólo permite poder comprender los códigos de la tribu, sino también dominar las prácticas a un nivel óptimo que permite tener el reconocimiento del grupo, generando emociones positivas en la persona.

“Esto es el caso de 'Evert MJ', un chico de 18 años, el k-pop le dio la oportunidad de hacerse un hueco en el mundo del baile y encontrar cuál es su verdadero talento. Además, gracias a su grupo favorito, EXO, él pudo conocer muchas más amistades y, sobretodo, especializarse más en diferentes estilos de baile como Jazz, Impro y demás" (k-poper).

Lo mismo se aprecia en los otakus, procedente de la cultura oriental que sólo al verlos generan una reacción etnocéntrica. Sus cabellos negros, medianamente largos, con el flequillo a un lado, el uso de laca, su delineamiento de los ojos, son rasgos peculiares de los otakus.

"Me motiva a venir acá el conocer a la gente... Más a los jóvenes... a conocer más de la cultura asiática, qué animes les agrada y recomendar sobre animes también. Aquí me encuentro con muchos amigos... Cuando vengo siento esa amistad, esa fraternidad de hace tiempo" (otaku).

c) Gusto: el placer también es aprendido. Los códigos culturales también pueden moldear nuestras emociones, principalmente en los primeros años, donde se marca el futuro de nuestra personalidad. Este es el caso de Javier, un niño estudiante del distrito de Chorrillos, que con tan sólo nueve años ya se sumerge dentro de las olas,

"porque vi que mi papá lo hace y quiero hacer todo lo que el haga" (surfista).

Sin embargo, el origen de estas tribus se puede rastrear en la adolescencia. En esta etapa, los individuos comienzan explorar más el exterior y buscan compararse e identificarse con otros. En las entrevistas, encontramos a personas con distintitas edades, la mayoría de estas remarcaban que iniciaron estas prácticas siendo adolescentes.

"Surfeo desde los 13 años, de los 365 días del año, paso unos 300 ó 305 en la playa" (surfista).

La miopía de la oferta se debe a la falta de herramientas metodológicas que permitan apreciar la existencia de tribus que necesitan de diversos productos para poder seguir 
existiendo. Aún mantenemos una oferta estandarizada e insípida: una oferta que hasta ahora no sabe lo que las personas realmente buscan. Este artículo nos hace reflexionar sobre la responsabilidad de las empresas limeñas hacia sus consumidores y nos preguntamos qué es la satisfacción para la disciplina del marketing.

La propuesta conceptual de tribu de consumo (basado en la etnografía) permite un mejor acercamiento entre el mercado y la sociedad. Este enfoque nos da una mirada distinta y nos permite encontrar nuevas oportunidades de negocios y nuevas formas de comunicar los productos de una forma más humana. El placer es el común denominador por el cual se conforman las tribus, es lo que explica el porqué están juntos, el porqué conviven. El estar juntos afianza el significado que tienen de sus elementos o prácticas que realizan, generándose así una fuerte integración. Vemos que las personas van buscando espacios donde puedan encontrar protección, reconocimiento y felicidad.

En suma, a pesar de este sistema de consumo imperante (que enarbola la individualización) esta ha permitido que se refuercen vínculos entre los sujetos, más allá de los determinismos sociales, de género, geográficos o de clase; dando paso a mecanismos de identificación por consumo cultural. Estas identidades permiten una vinculación más firme y ligada al consumo que la segmentación deductiva clásica, porque se confirma de manera espontánea por sus miembros, adquiriendo legitimidad. Pero, sobre todo, porque genera un vínculo directo sobre los pensamientos, actitudes y actos de consumo.

Las oportunidades de auto-segmentar los públicos por tribus de consumo son infinitas en una sociedad globalizada e interconectada a través de las redes sociales, donde los consumidores se convierten (más que en públicos objetivos) en medios que producen y comparten los mensajes claves y valores de marcas.

\section{Fuentes consultadas}

\section{Arellano, R.}

_(2010). Al medio hay sitio. Lima: Planeta.

_(2004). Lima, ciudad de los Reyes, de los Chávez, de los Quispe... Lima: Epensa.

\section{Augé, M.}

_(1998a). Los no lugares. Espacios del anonimato. Barcelona: Gedisa.

_(1998b). Hacia una antropología de los mundos contemporáneos. Barcelona: Gedisa.

Baptista, P.; Fernández, C. y Hernández, R. (2008). Metodología de la investigación. México D. F.: McGraw-Hill.

\section{Bauman, Z.}

_(2010). Mundo consumo. Barcelona: Paidós.

_(1999). La globalización. Consecuencias humanas. Buenos Aires: Fondo de Cultura Económica. 
Bourdieu, P. (1988). La distinción. Criterio y bases sociales del gusto. Madrid: Alfaguara.

Braudillard, J. (1994). De la seducción. Madrid: Cátedra.

Deleuze, G. (2005). Lógica del sentido. Barcelona: Paidós.

Deleuze, G., y Guattari, F. (2004). Mil Mesetas. Valencia: Pre-Textos.

Díaz, E. (2000). Posmodernidad. Buenos Aires: Biblos.

Fasano, P. (2006). El chisme de la trama social de la pobreza. Buenos Aires: Antropofagia.

\section{García-Canclini, $\mathbf{N}$.}

_(1998). La globalización imaginada. México D. F.: Grijalbo.

_(1995). Consumidores y ciudadanos. México D. F.: Grijalbo.

_(1991). "El consumo sirve para pensar". Diálogos de la Comunicación. Revista de la Federación Latinoamericana de Asociaciones de Facultades de Comunicación Social, núm. 30, pp. 6-9. Extraída el 15/VIII/2016 desde

http://www.antropologiasyc-106.com.ar/constructores/33cap5_canclini.pdf

Giddens, A. (2000). Un mundo desbocado. Los efectos de la globalización en nuestras vidas. Madrid: Taurus.

Goffman, E. (1994). La presentación de la persona en la vida cotidiana. Buenos Aires: Amorrortu Editores.

\section{Golte, J.}

(2010). Polifacéticos. Jóvenes limeños del siglo XXI. Lima: Instituto de Estudios Peruanos. _(1987). Los Caballos de Troya de los invasores. Lima: Instituto de Estudios Peruanos.

Guber, R. (2011). La etnografía. Método, campo y reflexividad. Buenos Aires: Siglo XXI. Extraída el 15/VIII/2016 desde http://es.slideshare.net/alemon2605/rosana-guber-laetnografa-mtodo-campo-reflexividad

Hevia, J. (2002). Lenguas y devenires en pugna. Lima: Universidad de Lima.

Huber, L. (2002). Consumo, cultura e identidad en el mundo globalizado. Lima: IEP.

Jacinto Pazo, P. (2012). Micronegocios vs. megamercados. Otros sentidos de identidad, distinción y consumo en los microempresarios de Lima Norte. Lima: UNMSM.

\section{Lipovetsky, G.}

_(1986). La era del vacio. Ensayos sobre el individualismo contemporáneo. Barcelona: Anagrama. 
(1988). El imperio de lo efímero. La moda y su destino en las sociedades modernas. Barcelona: Anagrama.

Lyotard, J. (1988). La condición posmoderna. Barcelona: Gedisa.

\section{Ortiz, $\mathbf{N}$.}

_(2016). “Etnomarketing: estrategias de negocios desde las raíces”. 360 Revista de Ciencias de la Gestión. Vol. 1, núm. 1, pp. 136-148. Extraída el 15/VIII/2016 desde http://revistas.pucp.edu.pe/index.php/360gestion/article/view/14874/15414 _(2015, febrero 24). "Tribus de Consumo: hacia la auto-segmentación de mercados". Extraída el 15/VIII/2016 desde http://etnomarketing.blogspot.pe/2015/02/antropologiadel-consumo-hacia-la-auto.html

Ortiz, N. y Chocce, M. (2015). "Formación de competencias creativas en la gestión de negocios". Revista Digital de Investigación en Docencia Universitaria. Vol. 9, núm. 2, pp. 105-114. Extraída el 22/VIII/2016 desde http://revistas.upc.edu.pe/index.php/docencia/ article/view/423/403

Rapaille, C. (2007). El código cultural. Bogotá: Norma.

Reynolds, M. (2012, febrero 21). “¿Cómo lograr que las personas vivan las marcas más que consumirlas?”. En blog Marcela Reynolds. Extraída el 20/IV/16 desde http://marcelareynolds.blogspot.pe/2012/02/paper.html

Rivera, J.; Arellano, R. y Molero, V. (2000). Conducta del consumidor. Madrid: ESIC.

Solomon, M. (2008). Comportamiento del consumidor. México D. F.: Pearson.

Signorelli, A. (1999). Antropología urbana. México D. F.: Anthropos.

Todorov, T. (1995). La vida en común. Madrid: Taurus.

Tomlinson, J. (2001). Globalización y cultura. México D. F.: Oxford University Press.

Veblen, T. (1955). Teoría de la clase ociosa. Buenos Aires: Fondo de Cultura Económica.

Veneziani, M. (2014). "Costumbres, dinero y códigos culturales: conceptos inseparables para la enseñanza del sistema de la moda". Cuadernos del Centro de Estudios en Diseño y Comunicación, núm. 48, pp. 81-93.

Yonnet, P. (2005). Juegos, modas y masas. Barcelona: Gedisa. 